\title{
ECTROMELIA
}

\section{A CASE REPORT}

BY

\author{
S. A. SELIGMAN \\ From the Department of Obstetrics and Gynaecology, King's College Hospital, London
}

(RECEIVED FOR PUBLICATION MAY 9, 1961)

The following case is considered worth reporting on account of the rarity of major degrees of congenital hypoplasia of the limbs.

\section{Case Report}

The mother, age 29 , was a multigravid patient having had one 12-week spontaneous abortion and a live normal baby for which caesarean section had been performed for a failed trial of labour; the infant weighed $7 \mathrm{lb} .10 \mathrm{oz}$. at birth. This pregnancy had been uneventful during the early months apart from a severe anxiety state; the patient had a hysterical personality, for which she required psychiatric treatment but no drugs were administered. There was no history of influenza or any other viral infection in early pregnancy and no anaesthetic was administered. The foetus presented by the breech and the malpresentation could not be corrected easily when an external cephalic version was attempted. In view of this and the history of the previous successful pregnancy, an elective caesarean section was performed at 39 weeks gestation. A living female ectromelus was delivered, which died 24 hours later.

External appearance. The body was that of a female measuring $33 \mathrm{~cm}$. from crown to rump, weight $4 \mathrm{lb} .13 \mathrm{oz}$. $(2,180 \mathrm{~g}$.). The upper limbs were completely absent and the lower limbs represented only by abnormal feet attached directly to the pelvic girdle (Fig. 1). The right appendage was $3.7 \mathrm{~cm}$. in length with the heel directed posteriorly with one rudimentary nail-bearing digit. The left appendage was $4.7 \mathrm{~cm}$. long with the heel directed laterally and with three nail-bearing digits.

Radiographs revealed one metatarsal in each appendage with one set of phalanges in the right and two in the left (Fig. 2). No bones were present beyond the upper limb girdle. There were no other skeletal deformities.

The placenta, membranes and umbilical cord appeared normal with two umbilical arteries present.

Internal Examination (Dr. J. M. Preece).

Heart and Great Vessels. Both atria appeared normal, as also did the atrial septum. The aorta was enlarged and arose from the right ventricle where its opening lay astride a high ventricular septal defect. The aortic valves and openings of the coronary arteries appeared normal. A minute pulmonary artery, with a considerable degree of stenosis at its origin, arose from the left ventricle and was connected to the aorta beyond the stenosis by a patent ductus arteriosus. The origin of the vessels from the thoracic aorta appeared normal, but the first two bronchial arteries were much larger than usual.

Kidneys. The right kidney was represented by a

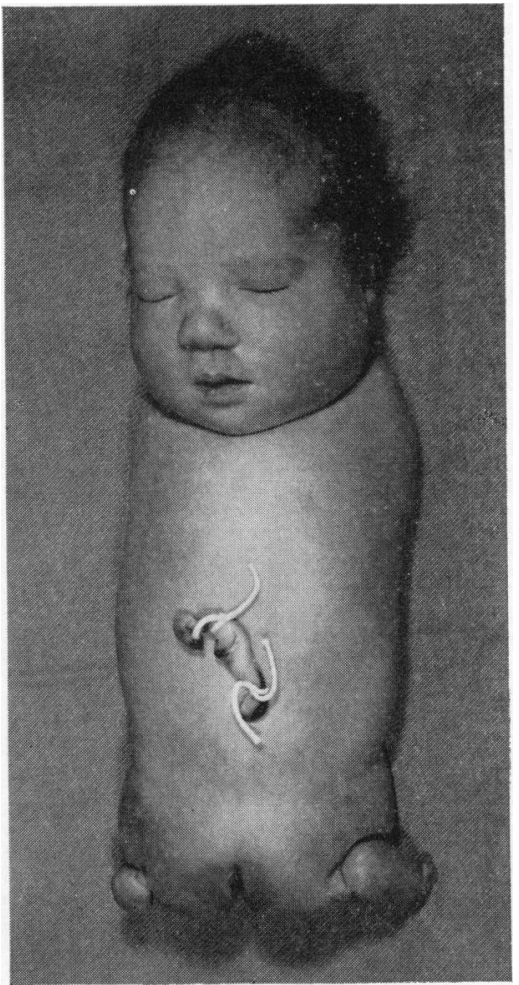

Fig. 1. 
lobulated cystic mass with no macroscopic evidence of remaining renal tissue. The left kidney appeared normal.

All the other organs appeared normal.

Organ Weights. Brain: 343 g.; spleen: 6 g.; left lung: 46 g.; left kidney: 7 g.; right lung: 46 g.; right kidney: $37 \mathrm{~g}$.; liver: 73 g.; thymus: 3 g.; suprarenals: 2 g.

Histology. The lung section showed congestion; the liver section showed small foci of haemopoiesis. Section of the right kidney showed it to consist of mesenchymal tissue with small numbers of grossly dilated ducts lined by cuboidal epithelium. No glomeruli were present. Section of the left kidney showed no abnormality. The pancreas, suprarenals and thymus were normal.

\section{Classification}

No satisfactory classification of developmental failure of the limbs exists. The definitions followed by most authors are those given in Blakiston's New Gould Medical Dictionary (1949) and are as follows:

Peromelia (G. pēros, maimed; melos, limb): Congenitally deficient, stunted or misshapen limbs.

Amelia (G. $\bar{a}$, not): Congenital absence of all extremities.

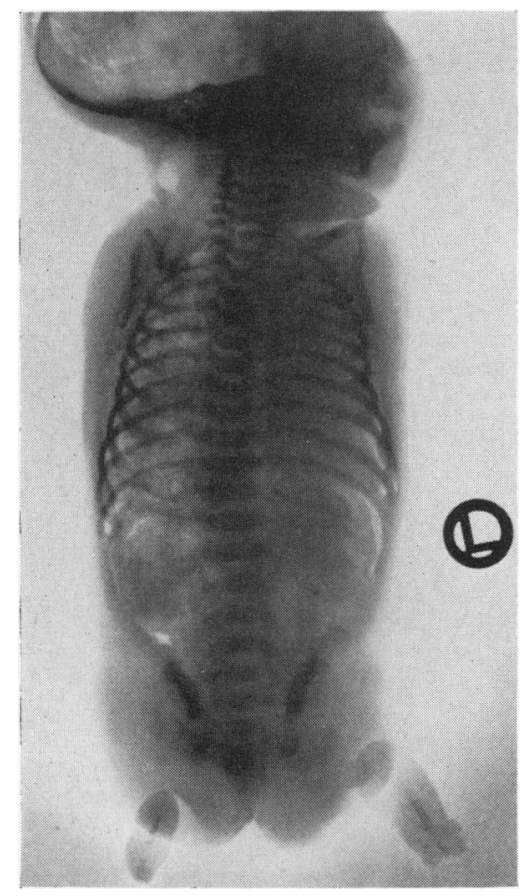

FIG. 2.
Ectromelia (G. ectrōsis, miscarriage): One or more congenitally imperfect limbs.

Hemimelia (G. hēmi, half): Incomplete or stunted extremities.

Phocomelia (G. phōkē, seal): Absence or markedly imperfect development of arms and forearms, thighs and legs, but with hands and feet present.

The term peromelia may be used generically and needs no further comment. Poidevin (1953) is of the opinion that, for true amelia, there should be no limb bones whatsoever beyond the limb girdles. On this basis he found only eight cases of amelia in the literature. A further case has since been described by Illemann-Larsen (1954). If phocomelia is defined by a similar strict definition, there should be no limb bones present between the limb girdles and the hands and feet, but this is impractical as no case of this nature has been described. The term is well worth retaining and should be extended to include any cases where hands or feet or both are attached almost directly to the trunk, giving the flipper-like appearance from which the name is derived. A fascinating historical review of these unfortunate individuals, including the famous 'Pepin', is given by Gould and Pyle (1898) who also describe examples of the other types of peromelia. A more recent case is that of 'Minnie', a 30-year-old negress with normal lower limbs (Hill, 1937).

The above definition of hemimelus is unsatisfactory and does not signify the essential nature of the lesion which is a deficiency of the distal parts of the limbs, which taper to a stump, while the proximal segments are normal. The term is little used. All remaining cases are classified as ectromelia, but the exact degree to which a limb must be stunted to come within the definition is not easy to assess. Some authors include such minor defects as the absence of digits. It is recommended that only major degrees of malformation should be included, but it seems impossible to define this further. It certainly cannot be assessed by interference with function.

\section{Aetiology}

Developmental failure of the extremities may be genetically determined or arise during foetal development. The role of Simonart's threads (amniotic bands) associated with the condition of graviditas examnialis is no longer considered an important factor in the production of these deformities. There are only two reports in the literature of peromelia in siblings. O'Brien and Mustard (1921) describe an ectromelus, which they call a phocomelus, occurring in a family in which three members were affected, whilst Flachsland (Gould 
and Pyle, 1898) reports on a woman who had three times borne children without arms and legs.

According to Arey (1954), all the materials for the limb are present within the limb bud when it first appears late in the fourth week. The limb primordium, even when barely discernible as a slight swelling, is capable of self-differentiation when it is isolated and without nerve supply. The normal source of induction is not obvious. By the application of metabolic procedures at the time of the development of the limbs, ectromelia has been produced in mammals (Kalter and Warkany, 1959). A wide range of teratogenic agents and methods have produced these deformities. These include deficiencies of vitamin $A$, riboflavine and folic acid; hypervitaminosis $\mathrm{A}$; the administration of nitrogen mustards, nucleic acid antagonists, insulin, tryptan blue and carbon monoxide. This last factor, which probably exerts its effect through the production of anoxia, may be of importance in cases of attempted suicide. Bette (1957) reports a case of ectromelia in association with this condition, and the author has recently had a similar case, whilst Ingalls (1960) records a further case as well as two other cases associated with anoxia in early pregnancy. The increasing habit of self- administration of cytotoxic drugs in order to induce abortion will probably produce further cases.

\section{Summary}

A case of ectromelia associated with other congenital deformities is described.

The classification and aetiology of developmental failure of the limbs is briefly discussed.

I wish to thank Sir John Peel, under whose care the mother was admitted, and also Dr. B. S. Cardell for the post-mortem report.

\footnotetext{
Arey, L. B. (1954). Developmental Anatomy, 6th ed. Saunders, Philadelphia.
Extremitäten-Missbildungen nach LeuchtgasverExtremitäten-Missbildungen nach Leuchtgasver-
giftung der Mutter; kasuistischer Beitrag zur Missbildungsforschung. (Malformations of extremities after maternal carbon monoxide poisoning; case report in the field of monster research.) Münch. med. Wschr., 99, 1246.

Blakiston's New Gould Medical Dictionary (1949). 1st ed., ed. H. W. Jones, N. L. Hoerr and A. Osol. Lewis, London.

Gould, G. M. and Pyle, W. L. (1898). Anomalies and Curiosities of Medicine. Saunders. Philadelphia.

Hill, L. L. (1937). Congenital abnormalities-phocomelus and congenital absence of radius. Surg. Gynec. Obstet., 65, 475.

Illemann-Larsen, G. (1954). Et tilfaelde af komplet ameli (a case of total amelia). Ugeskr. Laeg., 116, 928.

Ingalls, T. H. (1960). Ciba Foundation Symposium on Congenital Malformations, ed. G. E. W. Wolstenholme and C. M. O'Connor. Malformations, ed. G.

Kalter, H. and Warkany, J. (1959). Experimental production of congenital malformations in mammals by metabolic procedure. Physiol. Rev., 39, 69.

O'Brien, H. R. and Mustard, H. S. (1921). An adult living case of total phocomelia. J. Amer. med. Ass., 77, 1964.

Poidevin, L. O. S. (1953). Amelia. Review of the literature and report of a case. J. Obstet. Gynaec. Brit. Emp., 60, 922.
} 